\title{
APPLIANCE OWNERSHIP AND ASPIRATIONS AMONG ELECTRIC GRID AND HOME SOLAR HOUSEHOLDS IN RURAL KENYA
}

\author{
Kenneth Lee \\ Edward Miguel \\ Catherine Wolfram \\ Working Paper 21949 \\ http://www.nber.org/papers/w21949 \\ NATIONAL BUREAU OF ECONOMIC RESEARCH \\ 1050 Massachusetts Avenue \\ Cambridge, MA 02138 \\ January 2016
}

This research is supported by the Development Impact Lab (part of the USAID Higher Education Solutions Network), the Berkeley Energy and Climate Institute, and the Center for Effective Global Action. We are grateful to Hunt Allcott for helpful comments and suggestions, and to Susanna Berkouwer, Elisa Cascardi, Radhika Kannan, Anna Kasimatis, and Francis Meyo for excellent research assistance. All errors remain our own. The views expressed herein are those of the authors and do not necessarily reflect the views of the National Bureau of Economic Research.

NBER working papers are circulated for discussion and comment purposes. They have not been peerreviewed or been subject to the review by the NBER Board of Directors that accompanies official NBER publications.

(C) 2016 by Kenneth Lee, Edward Miguel, and Catherine Wolfram. All rights reserved. Short sections of text, not to exceed two paragraphs, may be quoted without explicit permission provided that full credit, including $(\subset$ notice, is given to the source. 
Appliance Ownership and Aspirations among Electric Grid and Home Solar Households in Rural Kenya

Kenneth Lee, Edward Miguel, and Catherine Wolfram

NBER Working Paper No. 21949

January 2016

JEL No. O18,Q42

\begin{abstract}
In Sub-Saharan Africa, there are active debates about whether increases in energy access should be driven by investments in electric grid infrastructure or small-scale "home solar" systems (e.g., solar lanterns and solar home systems). We summarize the results of a household electrical appliance survey and describe how households in rural Kenya differ in terms of appliance ownership and aspirations. Our data suggest that home solar is not a substitute for grid power. Furthermore, the environmental advantages of home solar are likely to be relatively small in countries like Kenya, where grid power is primarily derived from non-fossil fuel sources
\end{abstract}

Kenneth Lee

Department of Agricultural and

Resource Economics

University of California, Berkeley

Berkeley, CA 94720

kennethlee@berkeley.edu

Edward Miguel

Department of Economics

University of California, Berkeley

530 Evans Hall \#3880

Berkeley, CA 94720

and NBER

emiguel@econ.berkeley.edu
Catherine Wolfram

Haas School of Business

University of California, Berkeley

Berkeley, CA 94720-1900

and NBER

wolfram@haas.berkeley.edu 
Universal energy access has emerged as a major policy goal in Sub-Saharan Africa. However, there are active debates about the extent to which energy access should be driven by investments in large-scale infrastructure, such as grid connections, or small-scale decentralized solutions, such as solar lanterns and solar home systems. Recently, both the US Agency for International Development (USAID) and the UK Department for International Development (DFID) have announced high profile energy initiatives-similarly named Power Africa and Energy Africa, respectively - targeting the 70 percent of Sub-Saharan Africans who are believed to be living off of the electric grid. At the heart of both policies is a focus on expanding the market for solar lanterns and solar home systems, which we refer to collectively as "home solar."

Several factors have contributed to the enthusiasm for home solar. With energy-related emissions of greenhouse gases accounting for over three-quarters of global emissions, politicians, donors, and non-governmental organizations have been quick to highlight the renewable nature of the technology, particularly in developing countries that are still building out their electricity systems. In addition, recent innovations have increased the affordability of home solar by reducing solar prices and decreasing the power requirements for a variety of end uses (e.g., connectivity and computing through smartphones and tablets). Furthermore, by integrating mobile money payment technologies into their products, companies such as M-KOPA in Kenya have addressed the financing challenge and are providing poor, rural households with previously unaffordable home solar systems that can be paid for gradually over time. ${ }^{1}$

Not everyone, however, shares this enthusiasm for home solar. On the cost side, Deichmann et al. (2010) propose that decentralized renewable energy will be the lowest cost option for just a minority of households in Africa, even when taking into consideration the likely

\footnotetext{
${ }^{1}$ In addition to these factors, Jacobsen (2007) points to the private sector appeal of home solar, noting how decentralized solar first emerged during the late-1980s and 1990s, a period in which mainstream development policies emphasized economic liberalization, privatization, and market-based approaches to service provision.
} 
reductions in costs over the next 20 years. On the demand side, a recent household survey in Tanzania, conducted by the Center for Global Development, revealed that nearly 90 percent of households who already had "access to electricity outside of the national grid, such as solar power" still wanted a connection to the national grid. ${ }^{2}$ Writing at The Breakthrough Institute, Caine et al. (2014) caution that, "whatever the short-term benefit, a narrow focus on household energy and the advocacy of small-scale energy sources like solar home systems can, in fact, make it more difficult to meet the soaring increase in energy demand associated with moving out of extreme poverty." Broadly, policymakers have begun to move away from binary definitions of energy access to recognize variation in the service levels provided by home solar and grid connections with different levels of reliability (see, e.g., ESMAP 2015).

While there is a small but growing research literature on the economic impacts of electrification (see, e.g., Barron and Torero 2015), there is minimal data and evidence on how electricity is consumed in the developing world, and how electricity use relates to the type of energy supplied. In this paper, we summarize the results of a recent household appliance survey conducted in Western Kenya to provide descriptive evidence on how rural households with and without grid connections, and those with home solar systems, compare in terms of the appliances they own and the appliances they aspire to own.

Our data indicate that home solar users own quite different appliances compared to gridconnected households, and suggest that home solar does not satisfy the full range of household energy needs, given current appliance technologies. We also document planned expansions in centralized electricity generating capacity in a number of Sub-Saharan African countries, including Kenya. We find that the environmental advantages of decentralized solar are likely to be relatively small in countries like Kenya, where a large proportion of existing and planned grid

\footnotetext{
${ }^{2}$ See http://www.cgdev.org/blog/dfid-solar-only-approach-rural-electricity-africans-want-on-grid.
} 
electricity is generated without fossil fuels. This paper is organized as follows: Section I describes the data and setting, Section II presents the results, and Section III concludes.

\section{Data and Setting}

We analyze household survey data collected between February and August 2014 from 2,504 rural households in 150 communities in Busia and Siaya, two counties that are broadly representative of rural Kenya in terms of electrification rates and economic development. Our sample consists of 2,289 households that are not connected to the grid and 215 households that are connected to the grid. In each community, field enumerators sampled 15 unconnected households, and up to 4 connected households wherever possible, using a comprehensive census of residential structures conducted in 2013. At the time of the census, community electrification rates were low, averaging 5 percent for rural households. The sampling procedure-which is described in detail in Lee, Miguel, and Wolfram (2016) — ensured that the data are largely representative of the rural population in Western Kenya.

We collected data on the different types of energy used in each household. In our setting, home solar penetration is low despite low grid electrification rates. For unconnected households, the most common primary sources of energy are kerosene (92.4 percent), solar lanterns (3.6 percent), and solar home systems ( 2.2 percent). Only 8.7 percent of unconnected households use either a solar lantern or a solar home system as a primary or secondary source of energy. ${ }^{3}$

Based on this data, we divide our sample into three categories: (1) households that are connected to the national electric grid ( $\mathrm{n}=215)$, (2) households that are not connected to the grid but use home solar systems (i.e., solar lanterns or solar home systems) $(\mathrm{n}=198)$, and (3) households that are not connected to the grid and rely primarily on kerosene energy $(n=2,091)$.

\footnotetext{
${ }^{3}$ Households were asked to identify their "main" (primary) and "other" (secondary) sources of lighting energy.
} 
There is a wide range of products in the home solar market. Solar lanterns, which typically cost $\$ 10$ to $\$ 100$, offer less than 10 watts of power and are limited to lighting and mobile charging services. In contrast, solar home systems, which cost anywhere from $\$ 75$ to $\$ 2,000$, offer up to 1,000 watts of power and can power televisions, fans, and limited motive and heating power. The most popular solar home system in Kenya, M-KOPA, currently costs over \$200 and provides an 8 watt panel, two LED bulbs, an LED flashlight, a rechargeable radio and mobile charging adaptors. ${ }^{4}$ In comparison, residential grid connections support the full range of potential applications. Higher-end systems, accommodating the use of high-wattage appliances, are rare in Western Kenya and none of the households in our sample have such a system. In our data, the mean price paid for solar lanterns and solar home systems is $\$ 54.27$ and $\$ 234.37$, respectively. ${ }^{5}$ Most of the systems documented are used solely to power low-wattage appliances. For this reason, we group solar lanterns and solar home systems together in our analysis.

We asked household respondents to list all of the electrical appliances they own. We then asked respondents to name the appliances that they would ideally purchase next. After compiling a list of all owned and desired appliances, we divide the list into two categories based on typical required wattages. ${ }^{6}$ We define low-wattage appliances, such as mobile phones and radios, as those that can be powered using the most common solar lanterns and basic solar home systems found in the study region. High-wattage appliances are defined as those that require either higher-end solar home systems (which again are largely non-existent in our setting) or connections to the electric grid. Using these data, we present comparisons below across the three categories of households defined above in order to better understand how households compare in terms of appliance ownership and aspirations.

\footnotetext{
${ }^{4}$ Based on Alstone, Gershenson, and Kammen (2015) and M-KOPA (http://www.m-kopa.com/products/).

${ }^{5}$ Mean prices paid for solar lanterns and solar home systems are based on 113 and 51 responses, respectively.

${ }^{6}$ We assume that nearly all households with grid connections or home solar devices have electric lighting.
} 


\section{Patterns of Electrical Appliance Ownership and Aspirations}

Three patterns emerge in our data. First, home solar households have higher living standards than kerosene households, but differences in appliance ownership are not large. In Appendix Table A1, we summarize the key differences in observed characteristics between kerosene and home solar households. Both types are similar in that the majority of household respondents are primarily farmers by occupation, but home solar users are characterized by higher socioeconomic status across most measures: they are more educated, politically aware, have bank accounts, and live in households characterized by high quality walls (made of brick, cement, or stone, rather than the typical mud walls), more land and assets. These higher living standards, however, do not translate into meaningful differences in appliance ownership.

\section{[Insert Figure 1]}

In Figure 1, we present a summary of the appliance ownership survey data, grouping appliances into low-wattage (Panel A) and high-wattage appliances (Panel B). Horizontal bars indicate the proportion of households in each category that own (dark grey) and desire (light grey) each appliance type. Connected households clearly own the most appliances, which is expected given that both connectivity and asset ownership are positively correlated with income. The difference between home solar and kerosene households, however, is far more muted; neither type of household owns many appliances. With the exception of mobile phones and televisions, ownership levels for all appliances fall below 6 percent and 15 percent for kerosene and home solar users, respectively. ${ }^{7}$

\footnotetext{
${ }^{7}$ A number of households own appliances that they appear unable to use regularly. For example, 16 percent of kerosene households own televisions, which may be powered with car batteries. Electric iron ownership is likely to be largely "aspirational" among home solar consumers, as conventional irons require over 1,000 watts of power, far more than the 8 watts that the most common home solar systems in Kenya can accommodate.
} 
Second, both home solar and kerosene households reveal a strong desire to own highwattage appliances. The most desired appliances for kerosene users include televisions (39 percent) and irons (16 percent). Similarly, home solar users desire televisions (37 percent), irons (26 percent), and refrigerators ( 24 percent). Many of the most commonly desired appliances can only realistically be powered with connections to the electric grid, pointing to the limitations of the home solar systems commonly available in Kenya.

Third, despite having access to electric lighting, both connected and home solar households continue to purchase non-trivial amounts of kerosene. In Appendix Figure A2, we summarize monthly spending for non-charcoal energy sources for each household category. ${ }^{8}$ As expected, connected households have the largest total energy budget, spending $\$ 15.68$ per month on average. In comparison, kerosene and home solar users spend $\$ 5.42$ and $\$ 6.53$ per month, respectively. Surprisingly, all three types of households spend a similar amount on kerosene, ranging from $\$ 3.66$ for connected households to $\$ 3.90$ for kerosene households.

Although mean kerosene spending is similar, there are substantial differences in the proportion of households reporting zero spending on kerosene. For example, 33.4 percent of connected households reported that they did not spend any money on kerosene over the past seven days, compared to 23.7 percent and 2.5 percent of home solar and kerosene households, respectively. These figures suggest that a large proportion of home solar users - and even connected households - are unable to completely eliminate their use of kerosene. ${ }^{9}$ For connected households, these spending patterns may indicate underlying problems with the grid, such as blackouts and other forms of poor reliability, highlighting the need for an increased focus on

\footnotetext{
${ }^{8} \mathrm{We}$ asked connected households for the amount of the last monthly electricity bill. For kerosene and other sources of energy, we asked for the total amount spent over the past seven days and then estimated monthly amounts.

${ }^{9}$ Note that very few households report using kerosene to cook. Only 0.4 percent and 3.1 percent of unconnected households list kerosene as their primary and secondary source of cooking energy, respectively. In comparison, 94 percent of unconnected households list collected firewood as their primary source of cooking energy.
} 
improving the service quality of the electric grid. For home solar households, these patterns suggest that the current range of solar products do not provide sufficient lighting points within the home and must be complemented with kerosene lanterns.

\section{Discussion and Conclusion}

Solar lanterns and solar home systems are often framed as an important step up the "modern electricity service ladder" (see, e.g., Alstone, Gershenson, and Kammen 2015). The findings in our data are consistent with this description. Relative to kerosene, home solar users benefit from improvements in basic energy applications, such as lighting and mobile phone charging. Once households have access to these basic end uses, however, the appliances that they aspire to own next tend to require high wattage levels that cannot be accommodated by most home solar systems. Since the power supplied by these systems does not scale with demand, home solar is not a substitute for grid power. Unless there is a dramatic reduction in the price of high-wattage systems, it is unlikely that households will be able to "leapfrog" the electric grid in the same way that mobile phones allowed people to leapfrog fixed line telecommunications. Of course, decentralized solar may remain the most attractive option for a small number of isolated rural communities located far away from the national power grid.

Home solar still has the potential advantage of being cleaner than fossil fuel based energy alternatives. To evaluate their possible environmental advantages in Kenya and other countries, we document existing and planned sources of centralized electricity generating capacity in the region. In Figure 2A, we plot installed capacity, and the proportion of non-fossil fuel generation, for the top ten producers of electricity in Sub-Saharan Africa (SSA) and ten Newly Industrialized Countries (NICs) from other regions. Relative to the SSA countries, the NICs have much higher levels of installed capacity. However, the SSA countries generate power that is, on average, half 
as carbon-intensive as the NICs. In the NICs, non-fossil fuel capacity is 29.4 percent compared to 64.6 percent in the SSA countries. ${ }^{10}$

[Insert Figure 2A]

In the future, countries in Sub-Saharan Africa will continue to expand centralized electricity generating capacity to serve industrial, commercial, and urban customers. This will happen regardless of the proportion of rural households that adopts home solar. In the SSA countries that we examine, a large share of these capacity additions will feature non-fossil fuel technologies. Appendix Table A1 summarizes current and future installed capacity in Kenya, where several geothermal and wind projects are already under development. Over the next 15 years, installed capacity is expected to increase dramatically from 2,295 MW to 19,620 MW. Still, the proportion of non-fossil fuel sources will remain constant, at roughly 64 percent.

In Figure 2B, we plot current and future installed capacity targets for the ten SSA countries, based on publicly available sources. Almost all of the countries plan to increase installed capacity while maintaining or even increasing the share of power derived from nonfossil fuel sources. As countries move to further decarbonize their national grids, the potential environmental advantages of home solar will decline.

\section{[Insert Figure 2B]}

The energy infrastructure choices that Kenya and other African countries make over the next decade will have major implications for both their economic development and global climate change. Focusing on home solar alone is unlikely to promote economic development. As

\footnotetext{
${ }^{10}$ Figures $2 \mathrm{~A}$ and $2 \mathrm{~B}$ summarize plant capacities, while environmental emissions will be proportional to the energy produced by different types of plants. Unfortunately, we are unable to obtain predictions of plant capacity factors, although it is not a priori clear that the share of non-fossil fuel production would be lower or higher than the share of non-fossil fuel capacity based on capacity factors of similar types of plants in other countries.
} 
Kremer and Willis (2016) point out, investment choices today will impact the economics (and the politics) of future energy infrastructure investments. In order to understand the economic implications of different approaches to addressing energy poverty, more research is needed on household energy demand in low-income countries, and how improvements in the governance and service quality of electric utilities will influence this demand.

\section{References}

Alstone, Peter, Dimitry Gershenson, and Daniel M. Kammen. 2015. "Decentralized Energy Systems for Clean Electricity Access." Nature Climate Change 5: 305-314.

Barron, Manuel, and Maximo Torero. 2015. "Household Electrification and Indoor Air Pollution," unpublished working paper.

Caine, Mark, Jason Lloyd, Max Luke, Lisa Margonelli, Todd Moss, Ted Nordhaus, Roger Pielke Jr., Mikael Roman, Joyashree Roy, Daniel Sarewitz, Michael Shellenberger, Kartikeya Singh, and Alex Trembath. 2014. "Our High-Energy Planet: A Climate Pragmatism Project." The Breakthrough Institute. http://thebreakthrough.org/images/pdfs/Our-High-Energy-Planet.pdf.

Deichmann, Uwe, Craig Meisner, Siobhan Murray, and David Wheeler. 2010. "The Economics of Renewable Energy Expansion in Rural Sub-Saharan Africa." Energy Policy 39(1): 215-227.

ESMAP (Energy Sector Management Assistance Program). 2015. "Beyond Connections: Energy Access Redefined." http://www.worldbank.org/content/dam/Worldbank/Topics/Energy\%20and\%20Extract/Beyond_Connections_Energy_Access_Redefined_Exec_ESMAP_2015.pdf

Jacobsen, Arne. 2007. "Connective Power: Solar Electrification and Social Change in Kenya." World Development 35(1): 144-162.

Kremer, Michael and Jack Willis. 2016. "Infrastructure, Aid and Coordination." American Economic Review Papers and Proceedings, forthcoming.

Lee, Kenneth, Edward Miguel, and Catherine Wolfram. 2016. "Experimental Evidence on the Demand for and Costs of Rural Electrification," unpublished working paper. 
Figure 1-Electrical appliances owned and desired by rural households in Kenya

Panel A: Low-wattage appliances
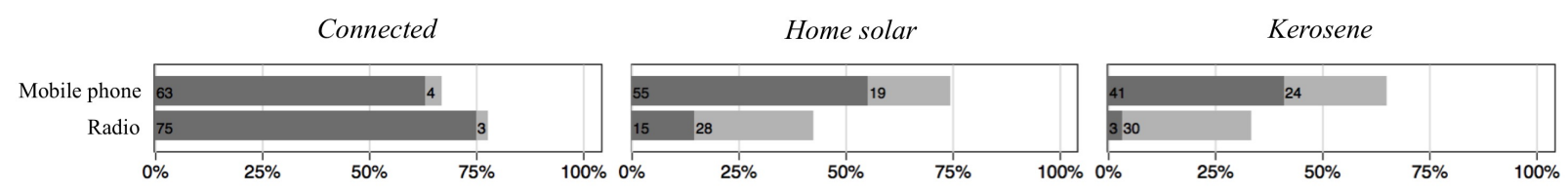

Panel B: High-wattage appliances
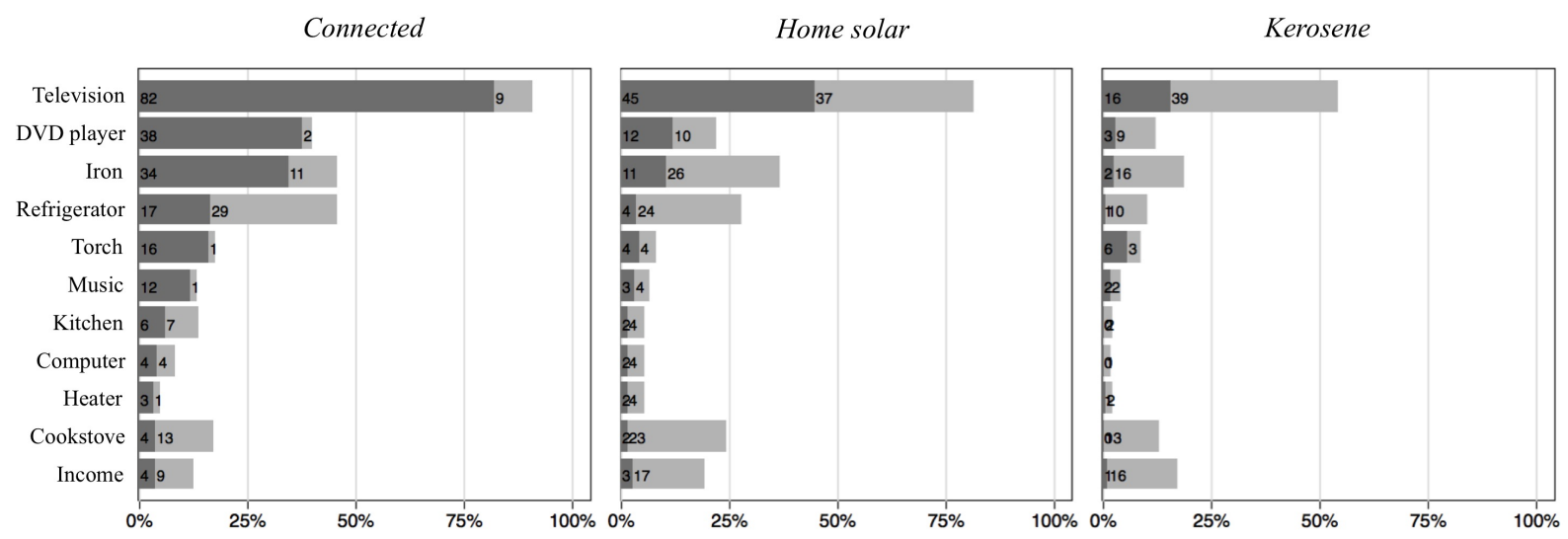

Owned appliance

Desired appliance

Notes: The label next to each bar indicates the proportion of households that own or desire each appliance. See Appendix Note A1 for additional details on appliance categories. 
Figure 2-Installed electricity generation capacity: Current and future targets

Panel A

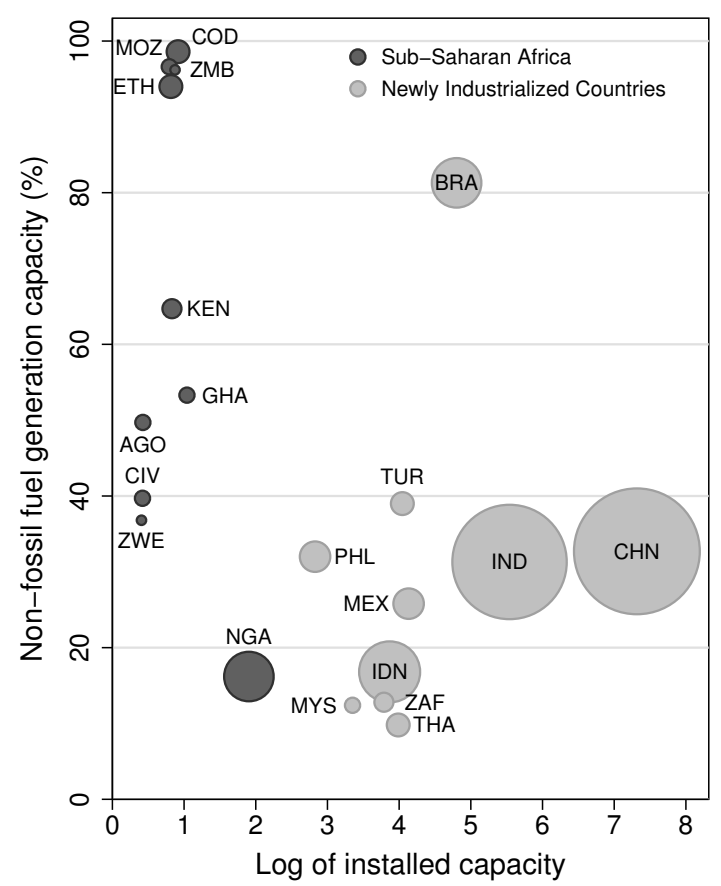

Panel B

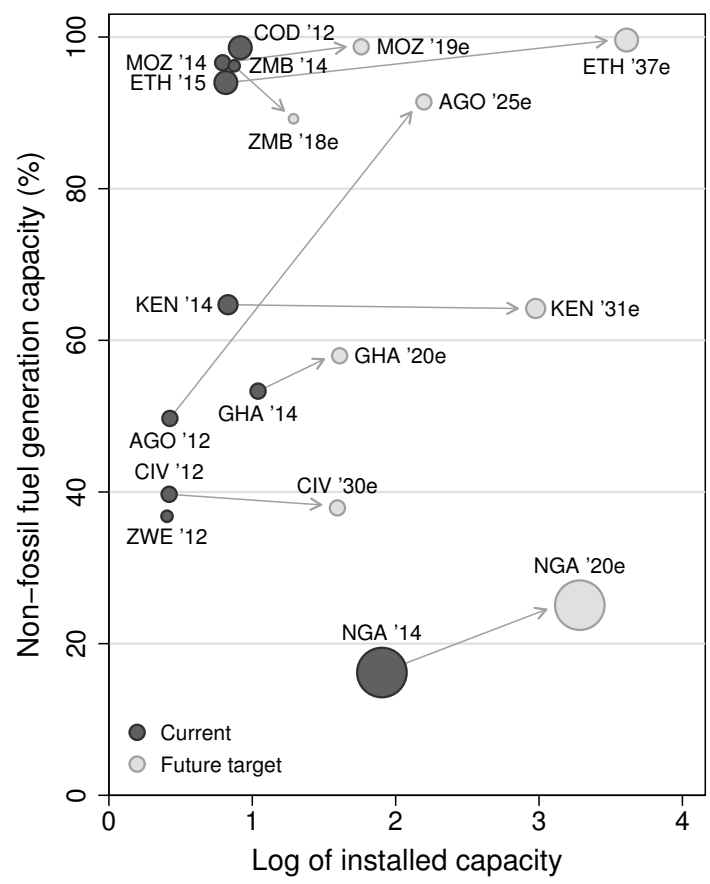

Notes: In Panel A, average non-fossil fuel generation is 64.6 and 29.4 percent for SSA countries and NICs, respectively. Markers are scaled by population. See Appendix Note 2 for detailed data sources. 


\section{Supplementary Appendix for Online Publication}

"Appliance Ownership and Aspirations among Electric Grid and Home Solar Households in Rural Kenya"

Kenneth Lee, Edward Miguel, and Catherine Wolfram

11 January 2016 
Table A1—Difference between kerosene and home solar households

\begin{tabular}{lccc}
\hline \hline & $\begin{array}{c}\text { Kerosene } \\
(1)\end{array}$ & $\begin{array}{c}\text { Home solar } \\
(2)\end{array}$ & $\begin{array}{c}p \text {-value of diff. } \\
(3)\end{array}$ \\
\hline Panel A: Household head (respondent) characteristics & & \\
Female (\%) & 63.1 & 60.1 & 0.40 \\
Age (years) & 52.5 & 50.6 & 0.12 \\
Completed secondary schooling (\%) & 12.1 & 26.3 & $<0.01$ \\
Married (\%) & 64.9 & 76.8 & $<0.01$ \\
Not a farmer (\%) & 22.1 & 26.3 & 0.19 \\
Basic political awareness (\%) & 10.7 & 18.7 & $<0.01$ \\
Has bank account (\%) & 16.0 & 42.4 & $<0.01$ \\
Panel B: Household characteristics & & & $<0.01$ \\
Number of members & 5.2 & 6.0 & 0.04 \\
Youth members (age $\leqq 18)$ & 3.0 & 3.3 & $<0.01$ \\
High-quality walls (\%) & 14.3 & 34.8 & $<0.01$ \\
Land (acres) & 1.9 & 2.8 & 0.77 \\
Distance to transformer (m) & 356.8 & 353.8 & $<0.01$ \\
Monthly (non-charcoal) energy (USD) & 5.42 & 6.53 & 0.06 \\
Monthly kerosene (USD) & 3.90 & 3.41 & $<0.0 .01$ \\
Panel C: Household assets & & & $<0.01$ \\
Bednets & 2.2 & 3.0 & \\
Sofa pieces & 5.6 & 10.1 & \\
Chickens & 6.5 & 12.1 & \\
Radios & 0.41 & 0.55 & \\
Televisions & 0.16 & 0.45 & \\
\hline Sample size & 2,091 & 198 & \\
\hline \hline
\end{tabular}

Notes: Columns 1 and 2 report sample means for unconnected households that primarily rely on kerosene and home solar at the time of the survey. Column 3 reports $p$-value of the difference between the means. Basic political awareness indicator captures whether the household head was able to correctly identify the presidents of Uganda, Tanzania, and the United States. Monthly (non-charcoal) energy expenditures includes kerosene expenditures. 
Table A2-Current and future installed capacity in Kenya

\begin{tabular}{lrrrr}
\hline \hline (in MW) & 2014 & $\%$ & $2031 e$ & $\%$ \\
\hline Hydro & 827 & 36.0 & 1,039 & 5.3 \\
Diesel & 751 & 32.8 & 1,955 & 10.0 \\
Geothermal & 593 & 25.9 & 5,530 & 25.6 \\
Gas turbine & 60 & 2.6 & 2,340 & 11.9 \\
Wind & 26 & 1.1 & 2,036 & 10.4 \\
Nuclear & 0 & 0.0 & 4,000 & 20.4 \\
Coal & 0 & 0.0 & 2,720 & 13.9 \\
Other & 38 & 1.7 & 0.0 & 0.0 \\
\hline Total & 2,295 & 100.0 & 19,620 & 100.0 \\
Fossil & 811 & 35.3 & 7,015 & 35.8 \\
Non-fossil & 1,484 & 64.7 & 12,605 & 64.2 \\
\hline
\end{tabular}

Notes: Breakdown of 2014 installed capacity is obtained from the website of Kenya's Energy Regulatory Commission. Breakdown of 2031 installed capacity is based on the Government of Kenya's Vision 2030: Least Cost Power Development Plan. Fossil fuel energy sources include coal, gas turbines (LNG), and diesel. In the planning documents, an additional 2,000 MW of electricity will be imported through regional interconnections with Uganda, Tanzania, and Ethiopia in 2031. These imports will consist primarily of hydroelectric power sources from Ethiopia and Uganda. 
Figure A1-Monthly spending on all energy sources (excluding charcoal)

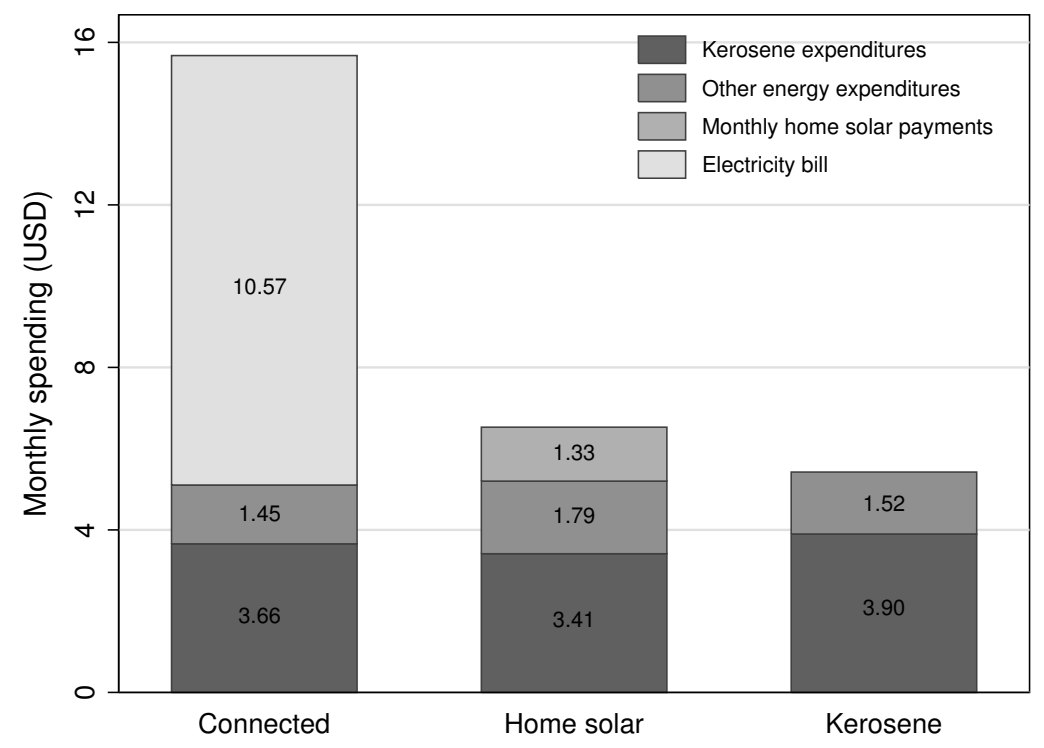

Notes: Other energy expenditures includes batteries, car battery charging, fuel for generators, and mobile charging. Monthly amounts for kerosene and other energy expenditures are estimated based on household responses to total spending amounts over the last seven days. 


\section{Note A1-Additional notes for Figure 1}

Based on a survey of 2,504 connected and unconnected households in Western Kenya. Households are divided into three categories: (1) connected to the grid $(n=215)$, (2) unconnected to the grid but using home solar (e.g. solar lanterns or solar home systems) $(n=198)$, and (3) unconnected to the grid with no home solar $(n=2,091)$. For each item, the bars indicate the proportion of households in each group declaring that they either own (dark grey) or desire (light grey) the appliance. Electrical appliances are divided into two categories based on required wattages. Low-wattage appliances can be powered using most solar home products. High-wattage appliances require higher power systems or connections to the grid. In addition, "torch" refers to rechargeable lanterns, "music" includes stereo systems and electronic musical instruments, "kitchen" includes blenders, kettles, microwaves, toasters, water coolers, and food processors, and "income" includes large appliances that are typically used for income-generating purposes, including posho mills, welding machines, blowdryers and shavers, water pumps, and battery chargers.

\section{Note A2-Data sources for Figure 2}

In this note, we summarize the data sources used to construct Figure 2.

I. Newly Industrialized Countries (NICs)

All estimates of installed capacity, non-fossil fuel generation and population are obtained from The World Factbook. The list of NICs includes China (CHN), India (IND), Indonesia (IDN), Brazil (BRA), Mexico (MEX), Philippines (PHL), Turkey (TUR), Thailand (THA), South Africa (ZAF), and Malaysia (MYS). Estimates for installed capacity range in date from 2012 to 2014.

\section{Sub-Saharan Africa (SSA)}

We focus on the top ten electricity producers in Sub-Saharan Africa based on The World Factbook's 2012 rankings. The list of SSAs include Nigeria (NGA), Ethiopia (ETH), Democratic Republic of the Congo (COD), Kenya (KEN), Ghana (GHA), Mozambique (MOZ), Cote dIvoire (CIV), Angola (AGO), Zambia (ZMB), and Zimbabwe (ZWE). For the NICs, we rely solely on The World Factbook estimates. For the SSAs, we examine current and future installed capacities more closely, referring to all types of publicly available sources online. Population estimates are obtained from The World Factbook 


\section{a) Nigeria (NGA)}

There are a variety of estimates for recent installed capacity and non-fossil fuel generation. These include USAID Power Africa, which estimates 6,000 MW of current installed capacity and non-fossil fuel generation of $20-30 \%$. We use an alternative, more detailed source, energypedia.info, which provides a list of grid-connected power plants in Nigeria. We exclude the 2015 plant from the list and estimate 2014 installed capacity to be 6,713 MW with $16.19 \%$ coming from non-fossil fuel sources. However, it should be noted that in Nigeria, there is a discrepancy between installed capacity and actual capacity due

to gas shortages. For future installed capacity, we use the estimates on energypedia.info that cite "The Presidency of the Federal Republic of Nigeria, August 2013, Roadmap for Power Sector Reform, Revision1, p. 24-25." We could not find the original source.

\section{b) Ethiopia (ETH)}

We refer to USAID Power Africa for estimates of 2015 installed capacity and non-fossil fuel generation. These estimates are dated to 2015 and cite the "Ethiopian Ministry of Water, Irrigation and Energy (2015)." We could not find the original source. For future installed capacity, we note that according to USAID Power Africa, "Ethiopia aspires to have a total installed generation capacity of 37,000 MWs and become a major power exporter [by 2037]." There are many sources that state that Ethiopia is targeting 37,000 MW by 2037. However, we could not find the Government of Ethiopia's "Power System Expansion Master Plan" which we assume provides the breakdown of future installed capacity. In the news, we find that hydropower covers some 80 per cent of total energy the country plans to generate, followed by geothermal sources ((Article \#1), and that "according to the EEPCo, Ethiopia has a potential to produce some 45,000 megawatts of electricity from hydro-power alone" (Article \#2). This leads us to the assumption that the majority of (if not all) new capacity will come from non-fossil sources. Furthermore, in a presentation by the Ministry of Water and Energy, delivered in 2013, the next 9,000 MW of capacity will come from hydro, wind, and geothermal. In Figure 2, we assume that all new capacity will come from non-fossil fuel sources.

\section{c) Democratic Republic of the Congo (COD)}

Estimates for 2012 installed capacity and non-fossil fuel generation are based on The World Factbook. We could not find any government projections for future installed capacity. 


\section{d) Kenya (KEN)}

Estimates for 2014 installed capacity are obtained from the Energy Regulatory Commission (ERC) website. Estimates for 2031 installed capacity are based on Kenya Vision 2030. In 2031, non-fossil fuel sources will consist of geothermal, nuclear, wind, and hydro. Fossil fuel sources will consist of coal, gas turbines (LNG), and diesel. These figures are also confirmed on the ERC Least Cost Power Development Plan. We exclude the 2,000 MW of imports that are shown in these figures, since we are primarily interested in installed capacity.

\section{e) Ghana (GHA)}

Estimates for 2014 installed capacity are obtained from the Ghana Energy Commission Current non-fossil fuel generation is based on the list of power plants provided on energypedia.info. In the Ministry of Energys Energy Sector Strategy and Development Plan, there is a target of 5,000 MW by 2015 with 10\% coming from (non hydro) renewable sources by 2020. According to USAID Power Africa, the 5,000 MW capacity is targeted by 2016, not 2015. There is no breakdown provided for the 5,000 MW of future capacity. In Figure 2, we assume that $10 \%$ of the 5,000 MW will come from renewable sources, and the remainder will come in the same proportion as the existing portfolio. We assume a target year of 2020 .

\section{f) Mozambique (MOZ)}

Estimates for 2014 installed capacity are obtained from energypedia.info. Estimates of future installed capacity are obtained from news articles citing the Government of Mozambique's (2015-2019) 5-Year Plan (Article \#1). We assume that the 3,600 MW of new capacity will consist entirely of hydro sources .

\section{g) Cote dIvoire (CIV)}

Estimates for 2012 installed capacity and non-fossil fuel generation are based on The World Factbook. Estimates for 2030 are based on a slide citing CI-ENERGIES 2013. The figure also appears here. We could not locate the original source.

\section{h) Angola (AGO)}

Estimates for 2012 installed capacity and non-fossil fuel generation are based on The World Factbook. Future installed capacity based on a Bloomberg article citing 9,000 MW of installed capacity by 2025. We assume that all of this new capacity will be hydro, based on the Energy Information Agency, which states that "Angola has also set an ambitious long-term goal of increasing hydropower capacity to 9,000 megawatts by 2025 by build- 
ing up to 15 new plants, with the help of foreign investment."

i) Zambia (ZMB)

Estimates for 2014 and 2018 installed capacity and non-fossil fuel generation are obtained from the Zambia Energy Regulation Board. We assume that the target completion year for the Kafue Gorge Lower Hydropower Project is 2018 based on this source.

j) Zimbabwe (ZWE)

Estimates for 2012 installed capacity and non-fossil fuel generation are based on The World Factbook. We could not find any government projections for future installed capacity. 